\title{
“FLIPPED CLASSROOM WITH A MOOC” AN E-LEARNING MODEL INTO A MATHEMATICS COURSE
}

\author{
Ana Paula Lopes ${ }^{1}$, Filomena Soares ${ }^{2}$ \\ ${ }^{1}$ Polytechnic of Porto (P.PORTO) / ISCAP - CICE / UIE, CEPESE (PORTUGAL) \\ ${ }^{2}$ Polytechnic of Porto (P.PORTO) / ESHT/ ESMAD (PORTUGAL)
}

\begin{abstract}
Nowadays, the online environment and technology tools are changing the way professors are developing and presenting course curriculum. Alongside this growth, we have assisted to the fast development of distance learning tools such as Open Educational Resources (OER) and Massive Open Online Courses (MOOCs) and the use of new teaching and learning models such the "Flipped Classroom" or "Inverted Classroom" model. This model is a pedagogical inversion of the traditional teaching paradigm: the main actions of the teaching and learning process that are used in classroom are now prepared by students previously before coming to class and provides the instructor with better opportunities for quality interaction with the students and helps students to develop a better understanding of the content and a deeper sense of community as a result of the student interaction in the course development and engagement.

The purpose of this paper is to present an experimental Higher Educational plan called "Flipped Classroom with a MOOC", within the project "Mathematics without STRESS - MOOC", that is using flipped classroom model as a pedagogical strategy. Furthermore, it relates such strategy with active learning practices and discusses its effectiveness, investigating how the flipping affects student's achievement and engagement. We also will present the results of a survey in which students were asked about "Flipped Learning with a MOOC" as a teaching method, using their experience from the course Mathematics Zero.
\end{abstract}

Keywords: Online Learning, Flipped Classroom, Higher Education, MOOC.

\section{INTRODUCTION}

Polytechnic of Porto (P. Porto), is a Higher Education Portuguese institution providing undergraduate and graduate studies, with more than 20000 students, teachers and researchers, which has a solid history of online education and innovation through the use of technology, has been particularly interested and focused on Massive Open Online Courses (MOOC) developments. Inside this huge academic community there is a continuous concern with the definition of strategies related to new ways of teaching and learning, to develop students' competences and promote students' academic success and future professional skills. Since the last four years, the e-IPP project - e-Learning Unit from P. Porto, is developing several Mathematics MOOCs, in order to improve the teaching-learning relationship in Higher Education courses.

Teaching is globalizing, the free supply of education (online) is expanding, and new teaching and learning methods are continuously emerging, developing and been tested such as Flipped Classroom and MOOC. In 2008, George Siemens (Athabasca University), Stephen Downes (National Research Council) and Dave Cormier (University of Prince Edward Island) created an open course called Connectivism and Connective Knowledge, also known as CCK08 [1]. It was the first course to incorporate open learning with distributed content, making it the first true MOOC and it attracted 2200 participants worldwide. Participants in the course were encouraged to develop their own online presence to add some value to this distributed resource network. The course authors then used a content aggregation tool in order to bring all the contents/contributions in one place. In the beginning MOOC were created for very specific pedagogical concepts, but quickly it took a huge dimension without necessarily following the initial design. For this reason, in 2012, Siemens [2] came up with the terms "CMOOC" and "XMOOC" to distinguish between 'connectivist' massive open online courses (cMOOCs) and Coursera and edX massive open online courses (xMOOCs). In the first one, participants are all considered teachers and learners and these often rely on learning communities, social media platforms and blogs, to promote interaction and develop contents, rather than an individual instructor and participants in a common student role as in XMOOCs. This second type of MOOC is essentially developed by world-leading campus-based universities (such as Stanford 
University or Massachusetts Institute of Technology) as a progress of an institutional strategy concerning on-campus teaching and digital technology [3]. In 2012, new endeavours such as edX [4], Coursera [5] and Udacity [6] introduced more than 200 online costless college courses, accessible to any person with an Internet connection [7]. These courses exploit web technologies to offer free online education to as many persons as possible. Still rising and, somehow, working "behind the curtain", MOOC seem to be carrying out an "open moving wave" in education. The years 2012 [8] and 2013 [9] are often mentioned as 'the MOOC years', but the "distance learning/teaching" paradigm goes far beyond our grandparents "era". With all the new technological advances of the "digital era" we are living in, Higher Education Institutions (HEI) are committed to raise the online access, in an opened or internal basis, to all kind of course resources like lecture notes, assessment materials, lecture recordings, among others, trying to take advantage of all the pedagogical/scientific potential these technological developments have to offer, maximizing their scope, while minimizing their eventual, and common, geographical restrictions.

"Open Educational Resources" (OER), has become a familiar term that we are often confronted with and is being widely discussed on a global level. Any kind of educational materials in the public domain or that are released with an open license that allow users to legally and freely use, copy, adapt, and re-share is considered to be an OER. If we look at UNESCO 2012 Paris Declaration [10], these resources are considered a strategic opportunity to improve the quality of education as well as facilitate policy dialogue, knowledge sharing and capacity building. The Declaration settles the relevance of OER and gives recommendations to governments and educational institutions, among others, around the globe. Consequently, the European Union has started a large-scale initiative on "Opening Up Education". According to the Europe 2020 Strategy [11], "smart growth" points to strengthening knowledge and innovation as driver forces of our future growth. This enrols improvements in the quality of educational systems, the research performance increase, innovation support and knowledge transfer, the promotion of a full and better use of information and communication technologies and to certify that new ideas can be turned into different products and services that generate growth, quality jobs and help to face global social challenges. Hence, it is our believe that OER in general, and MOOC in particular, can play an important and differentiating role as educational resources in this "digital era", as it becomes obvious that we are currently experiencing and facing significant modifications in Higher Education Institutions (HEI), and at all educational levels in general. The way we take advantage of all the new technologies developments, in a constructive knowledge improvement perspective, is a new challenge particularly to all $\mathrm{HEl}$ actors, as we must lead and support knowledge sources (and resources), validating processes and performances, "driving" each and every one involved into a proactive attitude towards future.

On the other hand, with the fast development in educational technology, many researchers and educators all over the world have recommended the use of technology through the curriculum as it produces good results in learning and understanding the concepts. Researchers and educators have been exploring alternative strategies and teaching methods to engage and motivate the students in learning process. The flipped classroom method or model is one of those alternatives. This model, called "Flipped Classroom", was developed by Jonathan Bergmann and Aaron Sams in 2000 [12], the pioneers of this trend, who at the time were chemistry teachers, at Woodland Park High School in Colorado, in an attempt to counter visible levels of student absenteeism, began to record their lessons and post them online, allowing students to access them remotely. Thus, the principal idea comes from reversing the traditional teaching paradigm, where the main phases of the teaching and learning process such as classroom activities and homework are reversed. The flipped classroom is then settled as a different course organization: where instructional content (e.g., pre-recorded video lectures) is assigned as "homework" - analyzed before coming to class and in-class time is spent working on problems, advancing concepts, and engaging in collaborative learning [13]. The flipped classroom may contain a big array of out-of-class activities further than lectures, including readings, homework, and supplemental videos ([14], [15], [16]). In-class activities differ widely, including activities such as role-play, debates, quizzes, and group presentations, amongst others [17]. In addition, the flipped classroom model allows the learners to learn at their own pace [18]. On the outcome of his experience, Tucker [19] has shown how Flipped Classroom leads (if properly designed/evaluated) to improve teaching-learning relationships producing a greater involvement and commitment of the students and a higher motivation as well.

The main purpose of this paper is to present an experimental study, that is being carried out, of a different approach to teaching Mathematics in Higher Education, called "Flipped Classroom with a MOOC", within the project "Mathematics without STRESS - MOOC", using flipped classroom model as a pedagogical strategy. 


\section{2 “MATHEMATICS WITHOUT STRESS" (M100S) - MOOC PROJECT}

"Mathematics without STRESS" (or in its original version - in Portuguese - Matemática 100 STRESS) was the first MOOC launched by P. Porto, for incoming HE students to prepare them for post-highschool courses using mathematics. This MOOC consists of three different Courses: Probability and Combinatorics, Introduction to Differential Calculus and Trigonometry and Complex Numbers. All these courses are created using the same guidelines based on the following division:

- Information Spot

- Math Diagnostic Test (MDT) - entry test, not mandatory;

- Modular subject division with two distinct subsections:

- Video-lectures

- Sequential mini-quizzes;

- "Doubt Ed" - Open Discussion forum;

- Final "Assessment Test"

- Global Course evaluation

The first course - Probability and Combinatorics (PC) - embraces 19 different modules/lessons, with 19 randomized quizzes and 24 video-lectures, distributed by the following topics:

- Random Experiment and Sample Space

- Events and Operations on Events

- Probability and Properties of Probability

- Exclusive Events

- Conditional Probability

- Intersection Events

- Law of Total Probability and Bayes Theorem

- Independent Events

- Fundamental Counting Principle

- Factorial of a Natural Number

- Arrangement without repetition

- Arrangement with repetition

- Permutations

- Pascal's Triangle

- Combinations

- Probability Distribution

- Newton's Binomial Formula

- Normal Model.

- Binomial Model

The second course - Introduction to Differential Calculus (IDC) - comprises 18 randomized quizzes and 65 video-lectures, separated in the following topics:

- Basic Calculus review

- Understanding functions

- Exponential Function

- Function Limit Theory

- Asymptotes

- Derivative Applications
- Polynomials Review

- Polynomial, Rational and Irrational Functions

- Logarithmic Function

- Function Continuity

- Function Derivative

- Second Derivative and Applications

The main page of the PC and IDC courses is presented in Fig. 1.
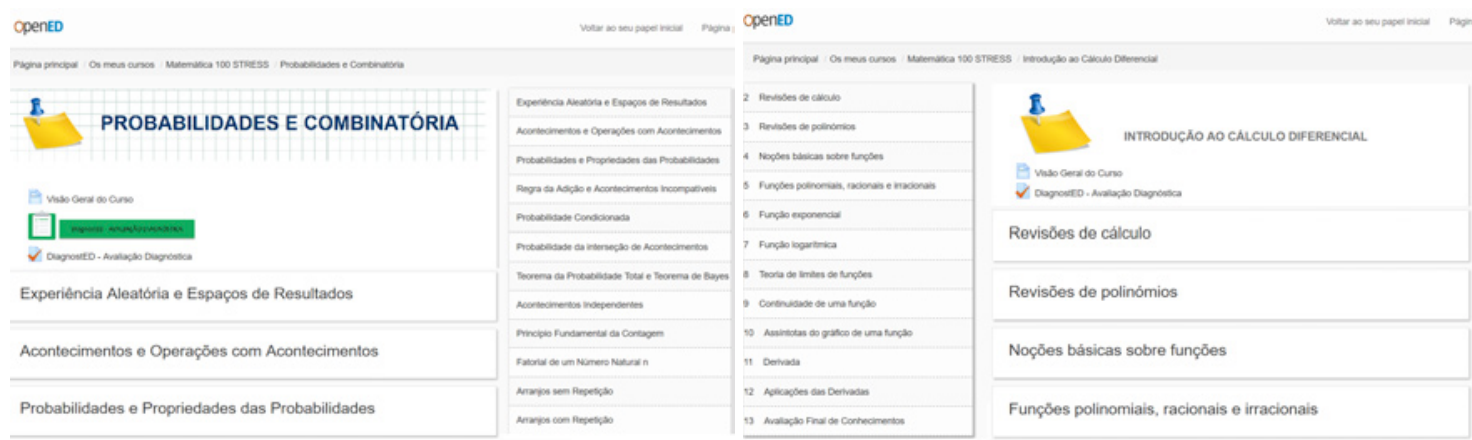

Figure $1-P C$ and IDC Course main page screenshot 
As we have already mentioned, all modules have similar structure (Fig. 2), they present an ordered set of video lectures where the relevant concepts are exhibited along with some illustrative examples. After watching each video (playing and replaying it as many times as they please), students can take a small quiz (Fig.3), with 5 random questions, and apply the concepts addressed in video lectures. In relation to these small quizzes, students can have multiple attempts at each one of them. This can help to transform the quiz taking process into an educational activity instead of a simple assessment. As the quiz is randomized, the student will get a new version in each attempt, which will be useful for practice purposes. Feedback is provided for each question, allowing the students to see one (of the possible) proposed solution, step by step, as showed in Fig.3. The Pool of Questions, from which the quizzes are randomised, is categorized separately by learning items (modules), as well as subdivided in difficulty levels.

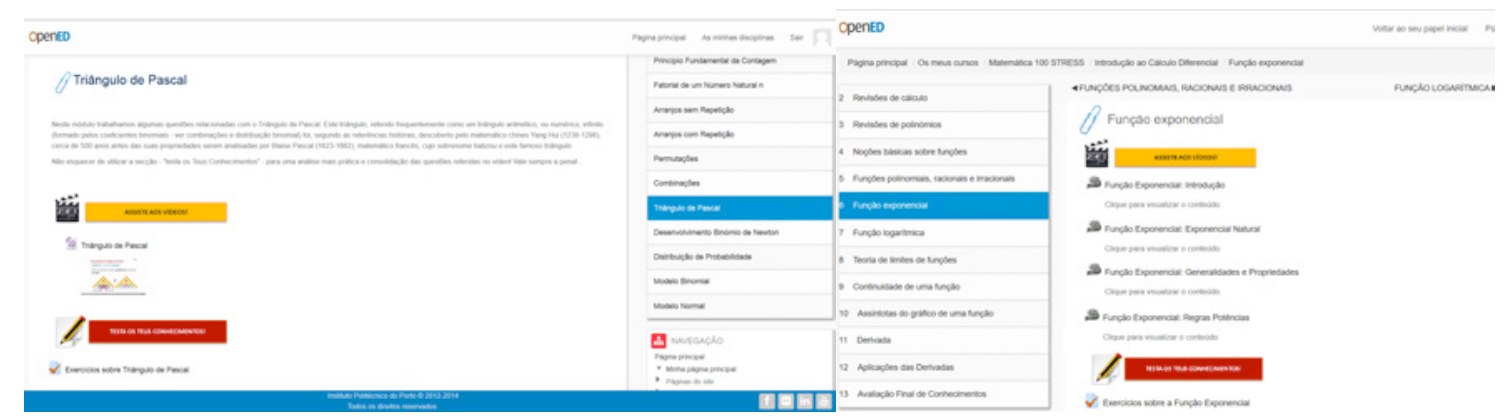

Figure 2 - Screenshot of the structure of "Pascal Triangle" and "Exponential Function" modules

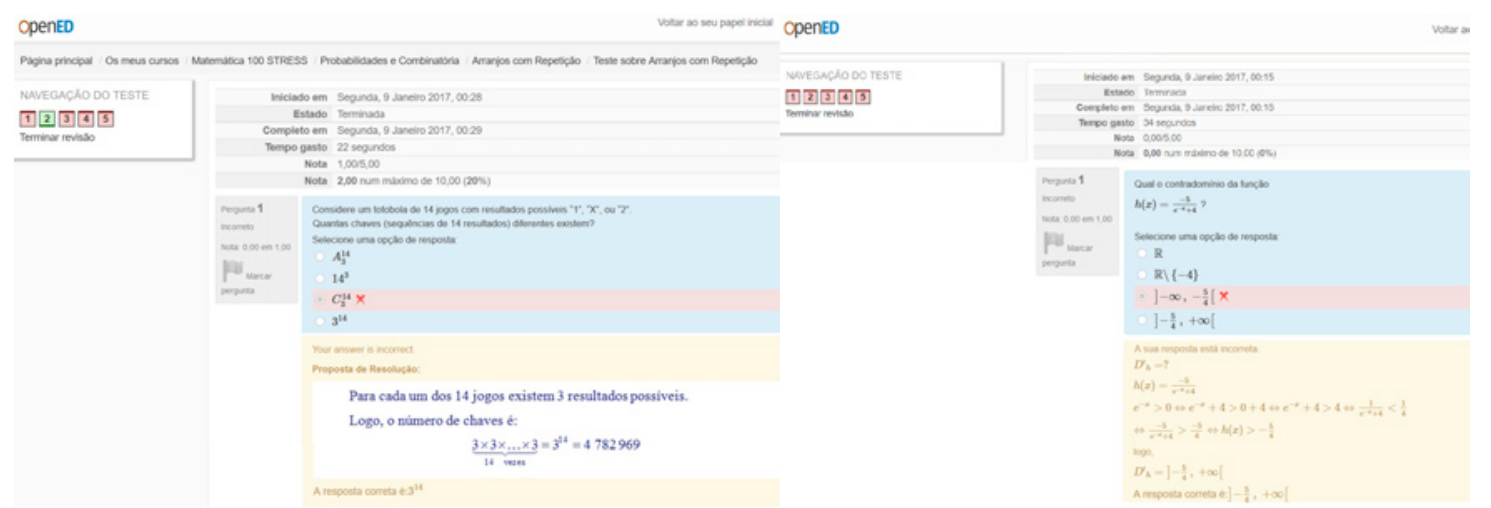

Figure 3 - Screenshot of the Multiple Choice Questions with General Feedback

\section{METHODOLOGY}

\subsection{Description of Mathematics Zero Course Design}

In order to get a better preparation for using the flipped-classroom approach for Mathematics Zero (MZ), we have studied and examined several flipped models and training. Therefore, we have studied, analyzed, debated and experienced the development of video lectures in various formats and as well as student-centered activities. Three sections of Mathematics: Probability and Combinatorics; Introduction to Differential Calculus; and Trigonometry and Complex Numbers, were taught in the 2015/2016 academic year. A total of 47 students from Zero Year Course participated in this study, divided into experimental and control groups. The experimental group (15) was taught Probability and Combinatorics using the flipped classroom method, while the control group (32) was taught by traditional teaching methods.

The traditional classes were provided with in-class lectures by the professor. This lecture typically lasted the entire 90 minutes of class, two times a week. In general, one sub-section took two or three weeks to complete. Once a sub-section was completed, students had a test with six questions on material directly related to theory and examples covered during the lectures.

The flipped class was scheduled one day per week for 90 minutes per class. Students of the flipped class were required to view one to six short lecture videos, each lasting between five to eight minutes, 
prior to the class meeting. The theory and examples found in the video lectures were similar to those presented in the lecture classes. The videos and playlists for M100S course can be found in the link:

https://www.youtube.com/channel/UCwNMLB6X3VJG7da6hXI4kiw. During the flipped class meeting, additional problems were worked in small groups, and the professor observed and supported student participation and progress, corrected students if errors were seen, and answered questions as they arose. Mostly, the solutions were presented first by students and occasionally by the professor if a problem was found to be difficult for them. Sometimes we asked for students, in the flipped class, to create and record their own videos of working examples, so later it gives the possibility to the professor review these. Like in the traditional classes, once a sub-section was completed, students had a test with six questions on material directly related to theory and examples covered in the videolectures. Although these were short ( 8 minutes maximum), we introduced, in several ones, a small group of questions and exercises, to be answered by students before continuing the video visualization in order to create some interaction, promote student engagement and, simultaneously, help them to overcome the tendency to be overconfident in their learning judgment (see some research results in [20]). Frequently, at the beginning of the class we straightly answered several questions related to an item in the video, but a lecture was never taught by the professor in the class. Both classes, traditional and flipped, were given the same tests, online homework and written homework. The only pedagogical difference among these students' segments was the instruction's method.

\subsection{Results}

A total of 47 students from Zero Year Course, aged 18 and 20 years old, participated in this study. The composition of the experimental group was 15 (9 male and 6 females) and the control group was 32 (18 male and 14 females). At the beginning of the academic year, an achievement test was administrated to all the students and this was given again as part of a final test. The test, scored between 0 and 20, was composed of 6 multiple choice questions and 3 groups of open-ended questions, all questions were carefully chosen and based upon material to be covered in the course. We analyzed the individual class changes in achievement from the pretest to the posttest and the differences in the tests grades between the two groups. A Student Attitude Survey (SAS) was administrated during the first week and the last week of classes. The questions were based in the reliability tests by UMASS's research team - The SimCalc Research team of the Kaput Center, University of Massachusetts Dartmouth - about Measuring Student Attitude in Mathematics Classrooms [21]. We used a 5 point Likert scale, "1" represented Very Unlikely and "5" represented Very Likely, to maintain stability given the intuitive understanding and insight of attitude concerning certain activities measured by several items. To the students from experimental group, four 1-5 Likert scale questions were still asked on the final survey, whether they would prefer a flipped math class over a traditional math class, even if online exercises (with feedback - solution step by step) helped them gain solid knowledge and skills in Math, whether video-lectures helped them understand the concepts studied in Math and if they would recommend a flipped math class to a friend. Moreover, two open ended questions about what was liked or not in the course, how it was taught and additional comments about how to improve the course.

An analysis was performed on both the pre $M Z$ course and post $M Z$ course assessment, as well as whether the flipped classroom model influenced student achievement. Table 1 shows the differences between the mean results, in the traditional classroom group and in flipped classroom group before and after they took the achievement test.

Table 1. Pre and Post MZ Course Mean Scores on the Achievement Test

\begin{tabular}{ccc} 
& Pre MZ Course & Post MZ Course \\
\hline Flipped Classroom & 11,8 & 14,1 \\
\hline Traditional Classroom & 12,5 & 14,4 \\
\hline
\end{tabular}

Source: Own elaboration

The results show that there was a little significant difference in the scores of those in the traditional courses and the flipped course; this suggests that both instructional methods were good at improving student achievement. Small differences occurred between the two groups for the SAS, suggesting that 
participation in either course improved a little bit their overall perceptions of learning Mathematics. Student answers to the open-ended questions about what was liked in the flipped MZ course, and additional comments support this belief as well. While several students mentioned the additional work outside of class due to the lecture videos and online exercises, they also saw its added value. Many students stated that video lectures helped them understand the concepts studied in MZ and online exercises helped them gain solid knowledge and skills in Mathematics.

\section{CONCLUSION}

The flipped classroom centers on changing the traditional development of activities in space and time to encourage students' enlarged participation and autonomy in their own learning process.

The purpose of this study was to examine whether different instructional practices, specifically $M Z$ flipped class with M100S MOOC versus MZ traditional class, influenced students' achievement and perceptions of learning in Mathematics. For this small sample of students, the flipped classroom approach found to have small significant impact on students than the traditional lecture model. Students in the flipped classroom show appreciation for the method and their survey results recommend this model.

In the traditional class students waited for professor to tell them what to learn, how to learn, when to learn it, and how to prove they had learned it. Even though we have motivated students, they tend to undertake a passive role in their learning. With the flipped model students are forced to play a much more active and responsible role in their own learning process. Learning is a challenge to be explored. As one student stated on the survey, "I liked video lectures because I was able to learn at my own pace and did not have to rush to write everything down in time. I would frequently pause the video to copy down definitions and examples, that way I was able to pay full attention to the explanations given instead of quickly trying to writing notes." One of the main advantages also mentioned by the students was the immediate feedback they got in the M100S MOOC. All the exercises in the MOOC are with feedback comments, with solution step by step, so if students get something wrong in their answer or if they don't know how to solve the exercise, they can see the explanation step by step of the proposed (re)solution. In the other hand, they do not have to wait until the professor has corrected their work. In class activities, the flipped model makes learning the center of the class. The students must work as hard as the professor. The class is more of a conversation instead of simple "monotonic" dissemination. As students study a given topic before class, their participation during class time is more active and may also explain their difficulties better. This offers the opportunity to personalize and differentiate the classroom easily, allowing an increase of individual accompaniment. Of course, professor's role in flipped class becomes different. Class time is not only a learning experience for the student but also for the professor. Identical advantages of the flipped model are mentioned in [22] and [23]. In summary, videos are playing a gradually important role in the way we teach. High-quality videos in degree education courses are the first step towards a MOOC world. The flipped classroom's dynamic methodology has positive effects on the experiences and learning process in higher education, particularly when we work with flipped classroom together with a MOOC, like we have done.

\section{REFERENCES}

[1] Downes, S. (2008). CCK08 - The distributed course, retrieved from https://sites.google.com/site/themoocguide/3-cck08---the-distributed-course

[2] Siemens, G. (2012, July 25). MOOCs are really a platform. [Web log message]. Retrieved from http://www.elearnspace.org/blog/2012/07/25/moocs-are-really-a-platform/.

[3] Armstrong, L. (2012, August 6). Coursera and MITx: Sustaining or disruptive? [Web log message]. Retrieved from http://www.changinghighereducation.com/2012/08/coursera-.html.

[4] M. Harvard. "edX," https://www.edx.org/.

[5] "Coursera," https://www.coursera.org/.

[6] "Udacity," https://www.udacity.com/.

[7] Kop, R. (2011). The challenges to connectivist learning on open online networks: learning experiences during a massive open online course. The International Review of Research in Open and Distance Learning, 12(3). 
[8] Pappano, L. (2012, November). The year of the MOOC. The New York Times. Retrieved from http://www.nytimes.com/2012/11/04/education/edlife/massive-open-online-courses-aremultiplying-at-a-rapid-pace.html

[9] Booker, E. (2013, January). Is 2013 year of The MOOC? Information Week. Retrieved from http://www.informationweek.com/education/online-learning/is-2013-year-of-themooc/240146431

[10] UNESCO (2012). UNESCO Releases the 2012 Paris OER Declaration at the World Open Education Resources (OER) Congress. Retrieved from, http://unesco.usmission.gov/oercongress-2012.html

[11] EUROPE 2020 (2010). A European strategy for smart, sustainable and inclusive growth. Retrieved from

http://ec.europa.eu/eu2020/pdf/COMPLET\%20EN\%20BARROSO\%20\%20\%20007\%20\%20Europe\%202020\%20-\%20EN\%20version.pdf

[12] Bergmann, J., \& Sams, A. (2012). Flip Your Classroom: Reach Every Student in Every Class Every Day. Arlington: ISTE.

[13] Findlay-Thompson, S., \& Mombourquette, P. (2014). Evaluation of a flipped classroom in an undergraduate business course. Business Education and Accreditation, 6, 63-71.

[14] Bergmann, J., Overmyer, J., \& Wilie, B. (2013, July 9). The Flipped class: Myths versus reality [Web log post]. Retrieved from http://www.thedailyriff.com/articles/the-flipped-classconversation-689.php

[15] Chen, Y., Wang, Y., Kinshuk, \& Chen, N. S. (2014). Is FLIP enough? or should we use the FLIPPED model instead? Computers and Education, 79, 16-27. doi:10.1016/j.compedu.2014.07.004

[16] Fautch, J. M. (2015). The Flipped classroom for teaching organic chemistry in small classes: Is it effective? Chemistry Education Research and Practice, 16(1), 179-186. doi:10.1039/c4rp00230j

[17] O'Flaherty, J., \& Phillips, C. (2015). The use of flipped classrooms in higher education: a scoping review. The Internet and Higher Education, 25, 85-95.

[18] Davies, R. S., Dean, D. L., \& Ball, N. (2013). Flipping the classroom and instructional technology integration in a college-level information systems spreadsheet course. Educational Technology Research and Development, 61, 563-580. doi:10.1007/s11423-013-9305-6

[19] Tucker, B. (2012) The flipped classroom. Retrieved from http://educationnext.org/the-flippedclassroom

[20] Szpunar, Karl K., Jing, Helen G. and Schacter, Daniel L.(2014) Overcoming overconfidence in learning from video-recorded lectures: Implications of interpolated testing for online education, Journal of Applied Research in Memory and Cognition, 3 (2014) pp 161-164. http://dx.doi.org/10.1016/j.jarmac.2014.02.001

[21] Brookstein, A., Hegedus, S., Dalton, S., Tapper, J. and Moniz, R. (2011). Measuring Student Attitude in Mathematics Classrooms. University of Massachusetts Dartmouth. Retrieved from http://www.kaputcenter.umassd.edu/downloads/products/technical_reports/tr4_student_attitude. pdf

[22] Fulton, K., 2012: Upside down and inside out: Flip your classroom to improve student learning. Learning \& Leading with Technology, 39(8), 12-17.

[23] Herreid, C. F., \& Schiller, N. A., 2013: Case studies and the flipped classroom. Journal of College Science Teaching, 42(5), 62-66 